\title{
Is There a Role for Biweekly Romiplostim in the Management of Chronic Immune Thrombocytopenia (ITP)? A Report of Three Cases
}

\author{
Jasjit Kaur Rooprai $\mathbb{D D}^{1}$ and Karima Khamisa $\mathbb{i D}^{2}$ \\ ${ }^{1}$ Faculty of Medicine, University of Ottawa, Ottawa, Ontario, Canada \\ ${ }^{2}$ Division of Hematology, Department of Medicine, The Ottawa Hospital, Ottawa, Ontario, Canada \\ Correspondence should be addressed to Jasjit Kaur Rooprai; jsing077@uottawa.ca
}

Received 19 August 2018; Accepted 30 September 2018; Published 24 October 2018

Academic Editor: Tomás J. González-López

Copyright (c) 2018 Jasjit Kaur Rooprai and Karima Khamisa. This is an open access article distributed under the Creative Commons Attribution License, which permits unrestricted use, distribution, and reproduction in any medium, provided the original work is properly cited.

Romiplostim is a peptibody, which stimulates platelet production by a mechanism similar to that of endogenous thrombopoietin. It has an established indication as second-line therapy in patients with chronic immune thrombocytopenia (ITP). The agent is typically administered weekly; however, there are instances where a biweekly (i.e., alternate week) dosing may be feasible in a select group of patients. We conducted a retrospective case review to evaluate the efficacy and safety of biweekly administration of romiplostim in maintaining a platelet count of $>30 \times 10^{9} / \mathrm{L}$ in three patients with chronic ITP. Treatment was started with a weekly injection $(1 \mu \mathrm{g} / \mathrm{kg})$ with a dose escalation to achieve a platelet count $>30 \times 10^{9} / \mathrm{L}$. Once stable on weekly romiplostim, these patients received biweekly administration. No bleeding complications were noted during biweekly dosing for these patients. The current findings suggest that lengthening the dose interval of romiplostim is feasible in select patients with chronic ITP to maintain stable platelet counts. Additional studies are therefore warranted to further evaluate biweekly dosing for romiplostim to increase convenience and decrease costs for patients with chronic ITP.

\section{Introduction}

Chronic idiopathic immune thrombocytopenia (ITP) is an autoimmune bleeding disorder characterized by low platelet counts often below $100 \times 10^{9} / \mathrm{L}$ for at least 12 months' duration [1]. Recent literature suggests that the pathogenesis of immune thrombocytopenia (ITP) is caused due to both autoantibody-mediated platelet destruction and suboptimal platelet production [2-6]. Most traditional ITP therapies have focused on either inducing short-term increases in platelet counts (via intravenous immunoglobulins (IVIg), steroids, and intravenous anti-D) or long-term maintenance of platelet counts using rituximab and splenectomy [4]. These treatments were effective in many patients but failed to achieve or maintain a durable response in certain patients and were associated with adverse effects [4]. In the past decade, thrombopoietin receptor agonists (TRAs) have been shown to induce increases in platelet counts in both healthy adults and patients with ITP, with an acceptable safety profile [4-7].

Romiplostim is a thrombopoiesis-stimulating protein, referred to as a peptibody, which stimulates platelet production by a mechanism similar to that of endogenous TPO [8]. Currently, both the American Society of Hematology ITP management guidelines and the International Consensus Report guidelines recommend the use of TRAs for adults with ITP that persists following splenectomy or in patients who are not candidates for splenectomy and for whom at least one other treatment has failed [9]. In addition, the 2015 assessment report released by the European Medicines Agency (EMA) on romiplostim concluded that TRAs can be considered as second-line treatment in nonsplenectomized patients [10]. Current evidence on the use of romiplostim in adults with ITP has demonstrated rapid and 
sustained platelet increases while reducing the use of concomitant medications and the incidence of bleeding [9]. Currently, it is dosed weekly to maintain platelet counts $>30$ $\times 10^{9} / \mathrm{L}$ (in International terms $>30,000 / \mu \mathrm{L}$ ). Usual starting dose is $1 \mu \mathrm{g} / \mathrm{kg}$ weekly, though some centers have been able to safely start patients on $2-3 \mu \mathrm{g} / \mathrm{kg}$ per week. Vials of romiplostim are only available in $250 \mu \mathrm{g}$ and $500 \mu \mathrm{g}$ sizes; titration by weight often involves discarding portions of these vials to meet exact dosing.

We report three cases of patients with chronic ITP who have maintained stable platelet counts $>30 \times 10^{9} / \mathrm{L}$ on biweekly dosing of romiplostim. The treatment of these three patients was started with a weekly injection, and the dose was escalated until a titrated dose was achieved that maintained platelet count $>30 \times 10^{9} / \mathrm{L}$. Patients were then switched to a biweekly schedule and were given a rescue dose (and steroids/IVIg) if platelet counts fell to below $<30 \times 10^{9} / \mathrm{L}$. The characteristics and outcomes of these patients are presented.

\section{Methods}

2.1. Study Design. This was a retrospective case series analysis of three patients with chronic ITP who were seen at the Ottawa Hospital (Ontario, Canada). These patients were subsequently followed in a community hematology clinic. Data were collected from electronic medical records for patients with chronic ITP, with treatment refractory disease and receiving romiplostim as a part of their therapy. Demographic and disease characteristics, including time of ITP diagnosis, previous ITP treatments, and concomitant ITP treatments, were recorded. This study was approved by the OHSN-REB (Ottawa Health Science Network Research Ethics Board), and written consent was provided by patients.

2.2. Definitions. Guidelines established by the American Society of Hematology (ASH) define a clinical response as a sustained platelet count $\geq 30 \times 10^{9} / \mathrm{L}$ and a complete response with a platelet count $\geq 100 \times 10^{9} / \mathrm{L}$ [1]. Further, it defines refractory ITP as severe ITP that persists after splenectomy or patients who respond temporarily to corticosteroid therapy or IVIg [1].

2.3. Case Presentations. We describe three cases of patients who were able to safely maintain their platelet counts on biweekly romiplostim (Table 1).

2.3.1. Case 1. A 62-year-old female diagnosed with ITP after presenting with persistent epistaxis, thrombocytopenia, and wet purpura at age 51; she was known to have a prior history of warm autoimmune hemolytic anemia (although this was stable). She was considered to have Evan's syndrome after her ITP diagnosis. Her other comorbidities included diabetes mellitus (type II) and developmental delay. Over the next 3 years, she had frequent relapses of her ITP requiring hospitalization for epistaxis. She underwent splenectomy within the first 3 months of her ITP diagnosis, and
TABle 1: Baseline demographic and clinical characteristics.

\begin{tabular}{lccc}
\hline Characteristic & Case \#1 & Case \#2 & Case \#3 \\
\hline Age of ITP diagnosis & 57 & 63 & 46 \\
Gender & Female & Female & Female \\
Weight & $60 \mathrm{~kg}$ & $120 \mathrm{~kg}$ & $80 \mathrm{~kg}$ \\
ITP etiology & Primary & Primary & Primary \\
Number of prior ITP therapies & 4 & 2 & 2 \\
Prior therapies for ITP & & & \\
Prednisone (maintenance) & $10 \mathrm{mg}$ & No & No \\
IVIg (\# of doses) & 16 doses & 4 doses & 21 doses \\
Rituximab & 8 doses & 4 doses & No \\
Splenectomy & Yes & No & Yes \\
Vincristine & Yes & No & No \\
Eltrombopag & Yes & No & No \\
Dexamethasone & Yes & No & No \\
\hline
\end{tabular}

eventually received eight courses of rituximab, multiple courses of IVIg and prednisone, and finally was started on romiplostim three years after her splenectomy. She maintained a stable platelet count on romiplostim $500 \mu \mathrm{g}$ weekly for 53 weeks. Due to platelet counts remaining in the $200-600 \times 10^{9} / \mathrm{L}$ range, she was switched to biweekly dosing of romiplostim $250 \mu \mathrm{g}$ and was able to maintain stable platelet counts for 11 consecutive weeks (Figure 1). She experienced a mild respiratory infection after the $11^{\text {th }}$ week mark which caused her platelet counts to fall. She received dexamethasone and IVIg as a rescue medication and eventually modified her romiplostim dosing schedule to alternate week dosing of romiplostim $250 \mu \mathrm{g}$ and $500 \mu \mathrm{g}$. While on biweekly romiplostim, she experienced no bleeding complications. However, given her cognitive issues, she felt weekly dosing a preferable option. Presently, her platelets remain in the 200 to $300 \times 10^{9} / \mathrm{L}$ range while on weekly doses of romiplostim, (presently at $230 \mu \mathrm{g}$ a week).

2.3.2. Case 2. A 65-year-old female was diagnosed with chronic severe thrombocytopenia at the age of 59. She had a number of comorbidities including diabetes mellitus (type II, poorly tolerant of steroids), chronic iron deficiency, obesity, and nonalcoholic steatohepatitis. She was initially put on intermittent IVIg therapy, with platelet levels increasing from $20-30 \times 10^{9} / \mathrm{L}$ to over $200 \times 10^{9} / \mathrm{L}$. The patient was not a candidate for splenectomy. The patient was started on romiplostim therapy at an initial dose of $100 \mu \mathrm{g}$ weekly and was able to maintain stable platelet counts for 38 weeks. Due to cost and convenience, a trial of biweekly dosing of romiplostim was initiated. The patient was able to maintain stable platelet counts for 131 consecutive weeks; however, due to a lapse in private medication coverage, the patient discontinued romiplostim altogether (Figure 2). Six weeks after her last romiplostim dose, she was given 4 doses of rituximab to maintain her platelet counts $>30 \times 10^{9} / \mathrm{L}$. Currently, she is on no treatment for ITP and is in partial remission, maintaining platelet counts in the range of $37-69 \times 10^{9} / \mathrm{L}$. While on biweekly romiplostim, she experienced no bleeding complications.

2.3.3. Case 3. A 52-year-old female was diagnosed with chronic refractory ITP at the age of 46 . She had a number of 


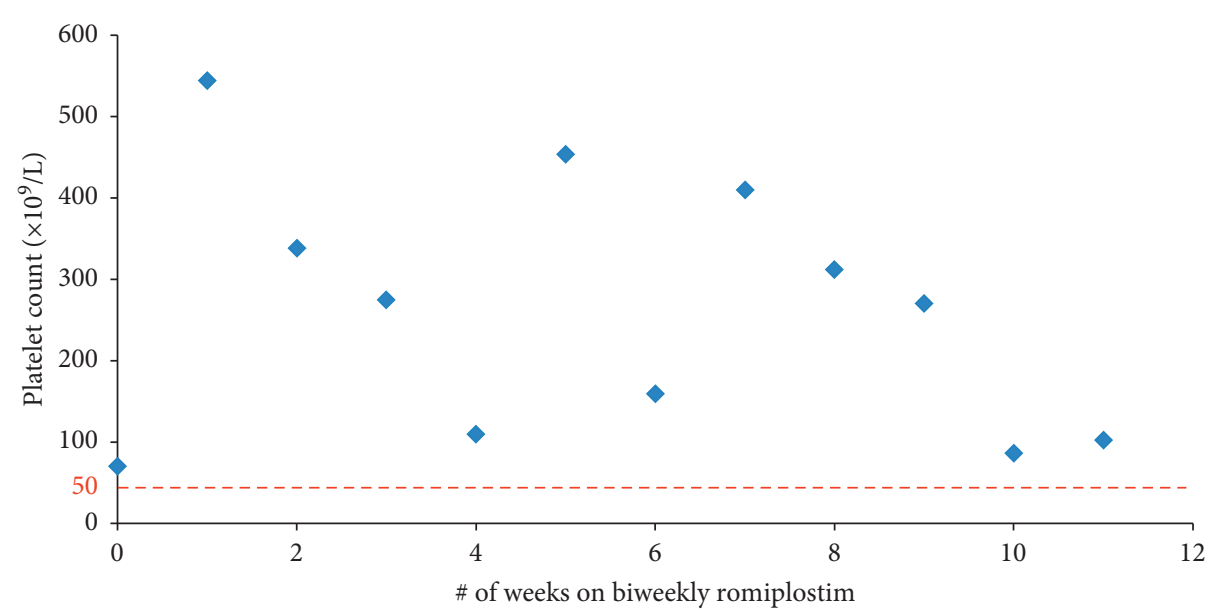

Figure 1: Case 1: biweekly romiplostim.

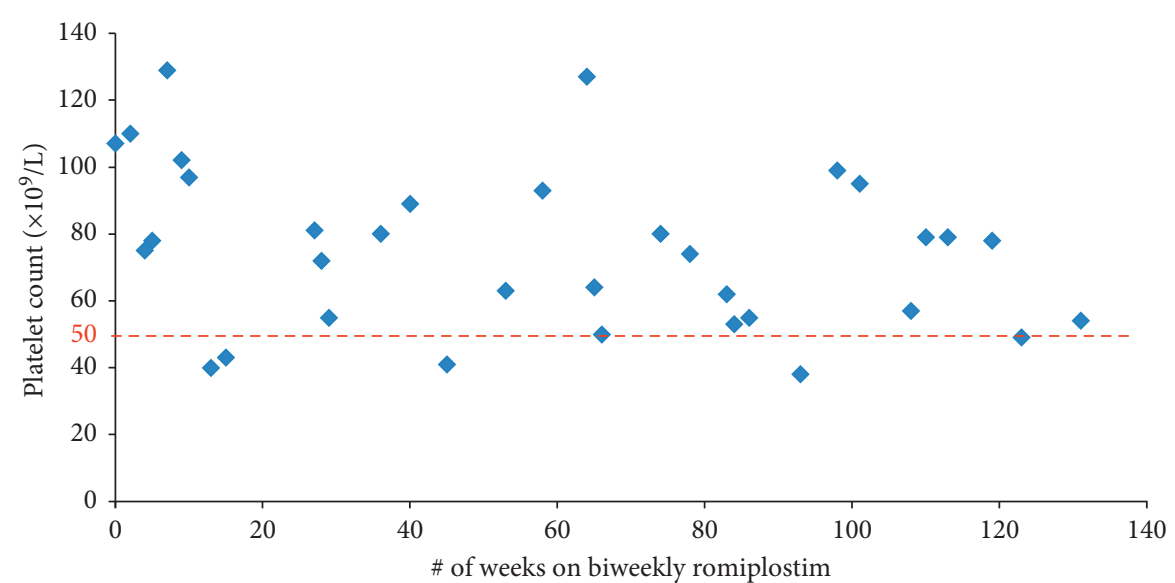

FIGURE 2: Case 2: biweekly romiplostim.

comorbidities including osteoporosis and type I diabetes mellitus. She was initially able to maintain a stable platelet count on prednisone 50-70 mg therapy for 2 years; however, due to her diabetes, she was weaned off prednisone. She underwent a splenectomy three years after her initial presentation; however, her platelet count remained under $10 \times$ $10^{9} / \mathrm{L}$ one-week postprocedure. She received multiple doses of IVIg and low dose prednisone to maintain her platelet count above $30 \times 10^{9} / \mathrm{L}$. Romiplostim was initiated 13 months postsplenectomy. She was started on weekly romiplostim $75 \mu \mathrm{g}$ therapy. She maintained stable platelet counts on weekly romiplostim dosing for 94 weeks before being switched to biweekly romiplostim $75 \mu \mathrm{g}$ therapy and was able to maintain stable platelet counts for 20 weeks (Figure 3). She had extremely high platelet counts on biweekly romiplostim $\left(400-700 \times 10^{9} / \mathrm{L}\right.$ range) allowing a trial of triweekly romiplostim dosing to be introduced. On q3weekly dosing, she was still able to maintain high platelet counts for 12 weeks (Figure 4), and thus, romiplostim therapy was discontinued altogether while monitoring the patient closely. The patient maintained a durable remission three years after her last dose of romiplostim. Like the other two patients, she experienced no bleeding complications while on biweekly dosing of the drug.

\section{Discussion}

In this paper, we report three cases of adult patients with chronic ITP who were administered biweekly dosing of romiplostim after achieving stable platelet counts (often with platelet counts well above $400 \times 10^{9} / \mathrm{L}$ ). Romiplostim, a TPO-receptor agonist, is a highly effective treatment for patients with chronic ITP following splenectomy or in patients who are not candidates for splenectomy and have failed one other form of treatment. Dosing is typically weekly via subcutaneous injection. Withholding the drug for a week is recommended if a patient's platelet count is above $400 \times 10^{9} / \mathrm{L}$ [7]. In some instances, withholding weekly dosing of the medication (despite platelet counts over $400 \times$ $10^{9} / \mathrm{L}$ ) can cause a paradoxical worsening of thrombocytopenia [7]. There is a paucity of the literature regarding the clinical use of biweekly dosing of romiplostim. However, a recent study by Park et al. did address this issue in patients with acute ITP [11]. While platelet counts remained labile in 


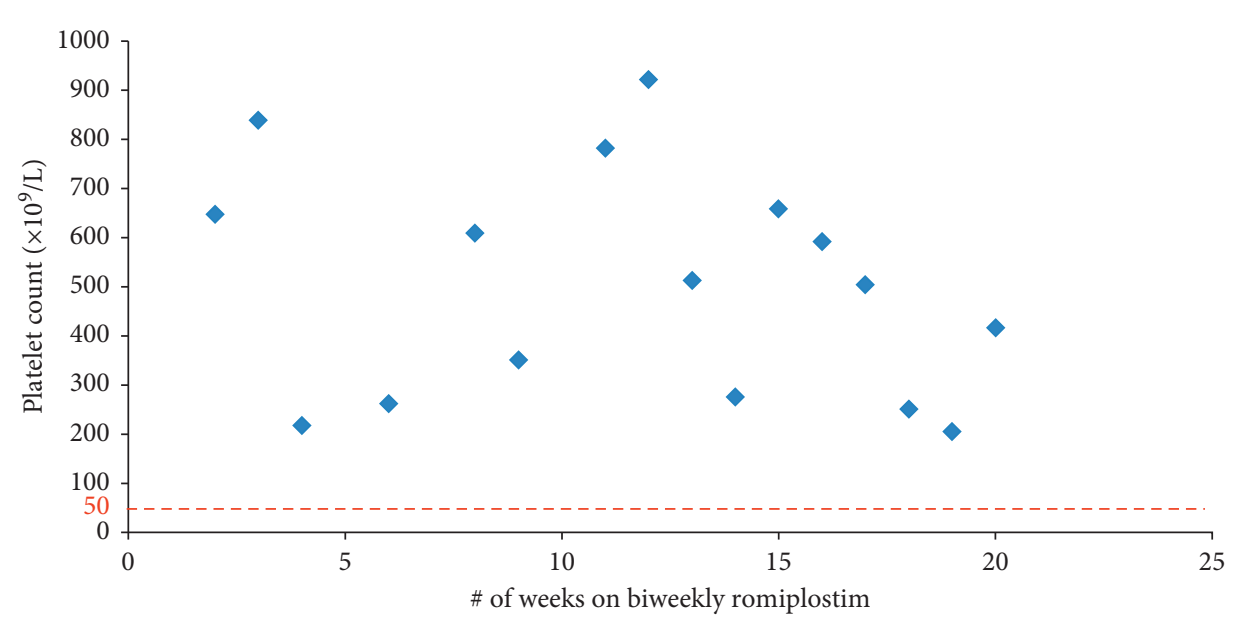

FIGURE 3: Case 3: biweekly romiplostim.

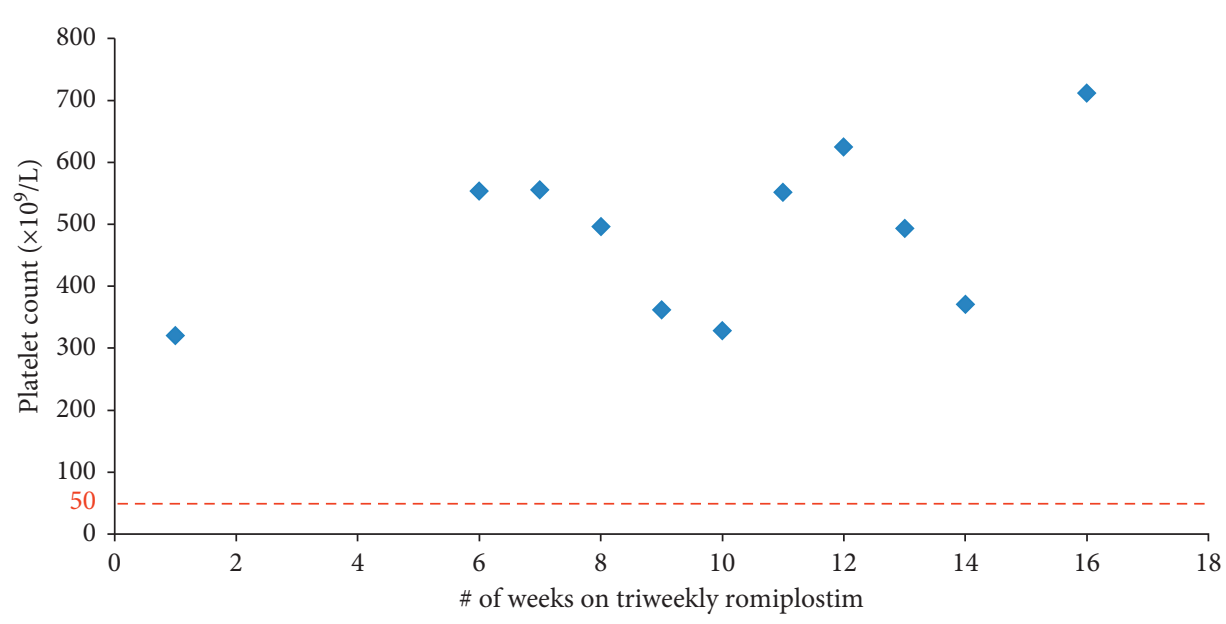

Figure 4: Case 3: triweekly romiplostim.

patients on biweekly dosing, no bleeding complications occurred in patients on this dosing schedule.

In this case series, we retrospectively evaluated the efficacy and safety of biweekly romiplostim therapy in three patients with chronic ITP, who had been previously stable on weekly therapy. Despite the differential characteristics of the described patients (Table 1), platelet responses were rapidly observed after romiplostim therapy (1-2 weeks) in all cases. All 3 patients had maintained stable platelet counts on weekly romiplostim for at least 38 weeks prior to being switched to the biweekly dosing schedule. All three patients maintained a platelet count $>30 \times 10^{9} / \mathrm{L}$ while on biweekly romiplostim therapy (Table 2 ). Park et al. previously reported that a biweekly romiplostim schedule was not effective in producing a stable platelet response in patients with chronic ITP [11]. However, the three patient cases presented in this paper suggest otherwise. Furthermore, Park et al. reported that a rapid drop in platelet count was observed in all cases shortly after switching to a biweekly dosing schedule [11]. However, in the three case studies being reported, no such rapid drop in platelet count was observed. This may be due to a longer duration of stability on weekly dosing ( 9 months versus 3 months in the Park study) before transitioning to biweekly dosing.

In another study by Sekeres et al., patients with myelodysplastic syndrome were administered either weekly or biweekly romiplostim [12]. Durable responses were attained in patients administered weekly or biweekly romiplostim, and no differences in adverse outcomes were noted between the two groups. This study also noted that thrombocytopenic patients do not need to achieve normal platelet levels to derive clinical and quality-of-life benefit from this therapeutic intervention [12]. The goal was to achieve platelet levels that obviated the need for transfusions and lowered the risks of spontaneous or traumatic bleeding [12].

Romiplostim is administered by subcutaneous injections in a dose based on a patient's body weight and platelet count. Romiplostim, however, is only available in two doses in prefilled vials, $250 \mu \mathrm{g}$ and $500 \mu \mathrm{g}$, costing approximately $\$ 882.50$ and $\$ 1765 \mathrm{Cdn}$, respectively [13]. The dose is potentially administered indefinitely for patients with chronic ITP. At the present time, in the Canadian health care system, the yearly medication costs between $\$ 45,890 \mathrm{Cdn}$ (for the $250 \mu \mathrm{g}$ weekly dose) and $\$ 91,780 \mathrm{Cdn}(500 \mu \mathrm{g}$ weekly dose). 
TABLe 2: Detailed summary of romiplostim dosing schedule.

\begin{tabular}{lccc}
\hline Parameter & Case \#1 & Case \#2 & Case \#3 \\
\hline Romiplostim started (postdiagnosis) & 3 years $(2015)$ & 2 years & 3 years \\
Trial 1 & & & $75 \mu \mathrm{g}$ \\
Dose & $500 \mu \mathrm{g}$ & $100 \mu \mathrm{g}$ & Weekly \\
Frequency & Weekly & Weekly & 94 weeks \\
Duration & 53 weeks & 38 weeks & $42-595$ \\
Platelet range $\left(\times 10^{9} / \mathrm{L}\right)$ & $31-722$ & $35-221$ & $75 \mu \mathrm{g}$ \\
Trial 2 & & & Biweekly \\
Dose & $250 \mu \mathrm{g}$ & $250 \mu \mathrm{g}$ & 20 weeks \\
Frequency & Biweekly & Biweekly & $217-922$ \\
Duration & 11 weeks & 131 weeks & $75 \mu \mathrm{g}$ \\
$\quad$ Platelet range $\left(\times 10^{9} / \mathrm{L}\right)$ & $86-454$ & $40-129$ & Triweekly \\
Trial 3 & $500 \mu \mathrm{g}$ & - & 12 weeks \\
Dose & Weekly & - & $321-625$ \\
Frequency & 42 weeks & - & Complete remission \\
Duration & $31-1277$ & Partial remission & \\
Platelet range $\left(\times 10^{9} / \mathrm{L}\right)$ & Stable & & \\
Current ITP status & & & \\
\hline
\end{tabular}

* On weekly dosing of romiplostim $230 \mu \mathrm{g}$.

However, certain patients, such as those presented in this case series report, can maintain stable platelet counts while on a biweekly dosing of romiplostim. On a biweekly dosing schedule, patients are able to save between $\$ 22,945$ and $\$ 45,890$ Cdn annually.

Interestingly, one patient (Case 3) achieved clinical remission after discontinuation of romiplostim. Several other studies have demonstrated sustained remission and a positive safety profile after discontinuing romiplostim, mainly in chronic relapsing or refractory ITP patients [14-17]. The mechanisms and factors of remission in patients with ITP remain unknown, although some studies suggest a restoration of immune tolerance and a decrease of inflammatory state after continuous treatment with TPO-receptor agonists through the stimulation of regulatory $\mathrm{B}$ and $\mathrm{T}$ lymphocytes $[18,19]$. We conclude that if a patient does appear to be entering a remission from ITP while on romiplostim, there may be a role for attempting biweekly dosing as part of a potential tapering strategy.

The half-life of romiplostim is estimated to be from 1 to 34 days, suggesting that lengthening the interval of romiplostim administration to more than a week may be possible in some patients, and should cautiously be evaluated on a case-by-case basis $[8,11,20,21]$. Early pharmacokinetic mathematical modeling studies further lend support to this possibility; weekly romiplostim dosing has a more predictable platelet count profile, but biweekly dosing can still lead to acceptable platelet counts, above the minimum requirements of $30 \times$ $10^{9} / \mathrm{L}$ [21]. The maintenance of stable platelet counts after initiating biweekly dosing of romiplostim suggests different physiological responses to romiplostim in ITP patients and highlights the importance of a close follow-up in these patients. Based on our real-life experience, a transition to biweekly romiplostim dosing may be attempted in those who have achieved clinical stability on a weekly dosing regimen for at least six months and have demonstrated platelet counts typically of $400 \times 10^{9} / \mathrm{L}$ or greater while on weekly dosing. This is especially helpful for patients with financial challenges. Finally, the alternate week dosing may be attempted in those that may be entering a remission from their ITP with eventual goal to stop all therapies.

\section{Conclusion}

In conclusion, lengthening the dosing frequency of romiplostim to biweekly may have a role to select patients with chronic ITP. Our data suggest that a trial of biweekly dosing may be implemented in patients who have been stable on weekly dosing for at least six months and may be entering clinical remission. All three patients reported in this case series had no adverse bleeding symptoms while on biweekly romiplostim dosing; one patient eventually experienced a sustained remission from her ITP. Although romiplostim is traditionally given on a weekly schedule, based on the present findings, it might be valuable to evaluate the efficacy of biweekly dosing on a case-by-case basis. In clinical practice, required doses and intervals are expected to differ between patients and the minimal effective dose to maintain adequate platelet levels should be determined individually. Further studies are warranted to determine which patients can safely be transitioned to biweekly dosing; this will ultimately reduce the cost of the medication and increase convenience to patients.

\section{Consent}

Written informed consent was obtained from the included patients for publication of this case report series.

\section{Conflicts of Interest}

J. R. has no conflicts of interest to disclose. K. K. has received Speaker's Fees for Alexion, Amgen, and Novartis.

\section{References}

[1] C. Neunert, W. Lim, M. Crowther, A. Cohen, L. Solberg, and M. A. Crowther, "The American Society of Hematology 2011 
evidence-based practice guideline for immune thrombocytopenia," Blood, vol. 117, no. 16, pp. 4190-4207, 2011.

[2] P. J. Ballem, G. M. Segal, J. R. Stratton, T. Gernsheimer, J. W. Adamson, and S. J. Slichter, "Mechanisms of thrombocytopenia in chronic autoimmune thrombocytopenic purpura. Evidence of both impaired platelet production and increased platelet clearance," Journal of Clinical Investigation, vol. 80, no. 1, pp. 33-40, 1987.

[3] D. Nugent, R. McMillan, J. L. Nichol, and S. J. Slichter, "Pathogenesis of chronic immune thrombocytopenia: increased platelet destruction and/or decreased platelet production," British Journal of Haematology, vol. 146, no. 6, pp. 585-596, 2009.

[4] D. B. Cines and J. B. Bussel, "How I treat idiopathic thrombocytopenic purpura (ITP)," Blood, vol. 106, no. 7, pp. 2244-2251, 2005.

[5] M. Chang, P. E. Nakagawa, S. A. Williams et al., "Immune thrombocytopenic purpura (ITP) plasma and purified ITP monoclonal autoantibodies inhibit megakaryoctopoiesis in vitro," Blood, vol. 102, no. 3, pp. 887-895, 2003.

[6] R. McMillan, L. Wang, A. Tomer, J. Nichol, and J. Pistillo, "Suppression of in vitro megakaryocoyte production by antiplatelet autoantibodies from adult patients with chronic ITP," Blood, vol. 103, no. 4, pp. 1364-1369, 2004.

[7] J. B. Bussel, D. J. Kuter, V. Pullarkat, R. M. Lyons, M. Guo, and J. L. Nichol, "Safety and efficacy of long-term treatment with romiplostim in thrombocytopenic patients with chronic ITP," Blood, vol. 113, no. 10, pp. 2161-2171, 2009.

[8] D. Hubulashvili and N. Marzella, "Romiplostim (Nplate), a treatment option for immune (idiopathic) thrombocytopenic purpura," Pharmacy and Therapeutics, vol. 34, no. 9, pp. 482-485, 2009.

[9] S. Chalmers and M. D. Tarantino, "Romiplostim as a treatment for immune thrombocytopenia: a review," Journal of Blood Medicine, vol. 6, pp. 37-44, 2015.

[10] European Medicines Agency, Assessment Report: Nplate, European Medicines Agency, London, UK, 2016.

[11] S. Park, S. S. Yoon, J. H. Lee, J. S. Park, J. H. Jang, and J. W. Lee, "Multicenter, prospective study to evaluate the efficacy of biweekly romiplostim administration in patients with immune thrombocytopenia," International Journal of Hematology, vol. 103, no. 1, pp. 44-52, 2016.

[12] M. A. Sekeres, H. Kantarjian, P. Fenaux et al., "Subcutaneous or intravenous administration of romiplostim in thrombocytopenic patients with lower risk myelodysplastic syndromes," Cancer, vol. 117, no. 5, pp. 992-1000, 2011.

[13] M. Pettigrew, K. Garces, R. Deuson, J. Kassis, and V. Laroche, "Comparative net cost impact of the utilization of romiplostim and intravenous immunoglobulin for the treatment of patients with immune thrombocytopenia in Quebec, Canada," Journal of Medical Economics, vol. 16, no. 2, pp. 318-326, 2013.

[14] M. Mahevas, O. Fain, M. Ebbo et al., "The temporary use of thrombopoietin-receptor agonists may induce a prolonged remission in adult chronic immune thrombocytopenia. Results of a French observational study," British Journal of Haematology, vol. 165, no. 6, pp. 865-869, 2014.

[15] L. Cervinek, J. Mayer, and M. Doubek, "Sustained remission of chronic immune thrombocytopenia after discontinuation of treatment with thrombopoietin-receptor agonists in adults," International Journal of Hematology, vol. 102, no. 1, pp. 7-11, 2015.

[16] C. Santoro, F. De Angelis, E. Baldacci et al., “Thrombopoietin receptor agonists in primary immune thrombocytopenia: evaluation of efficacy (response and sustained response off treatment) and safety in a single center population," Haematologica, vol. 99, no. 1, p. 205, 2014.

[17] M.-E. Mingot-Castellano, C. Grande-García, D. ValcárcelFerreiras, C. Conill-Cortés, and L. de Olivar-Oliver, "Sustained remission in patients with primary immune thrombocytopenia after romiplostim tapering and discontinuation: a case series in real life management in Spain," Case Reports in Hematology, vol. 2017, Article ID 4109605, 8 pages, 2017.

[18] W. Bao, J. B. Bussel, S. Heck et al., "Improved regulatory T-cell activity in patients with chronic immune thrombocytopenia treated with thrombopoietic agents," Blood, vol. 116, no. 22, pp. 4639-4645, 2010.

[19] H. Zhong, W. Bao, X. Li et al., "CD16 + monocytes control T-cell subset development in immune thrombocytopenia," Blood, vol. 120, no. 16, pp. 3326-3335, 2012.

[20] R. K. DasGupta, L. Levine, T. Wiczer, and S. Cataland, "Initial romiplostim dosing and time to platelet response in patients with treatment refractory immune thrombocytopenia," Journal of Oncology Pharmacy Practice, 2018.

[21] C.-H. Tsai, J. Bussel, A. Imahiyerobo, S. I. Sandler, and B. A. Ogunnaike, "Platelet count control in immune thrombocytopenic purpura patient: optimum romiplostim dose profile," IFAC Proceedings Volumes, vol. 47, no. 3, pp. 11800-11805, 2014. 


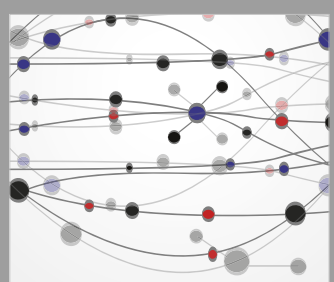

The Scientific World Journal
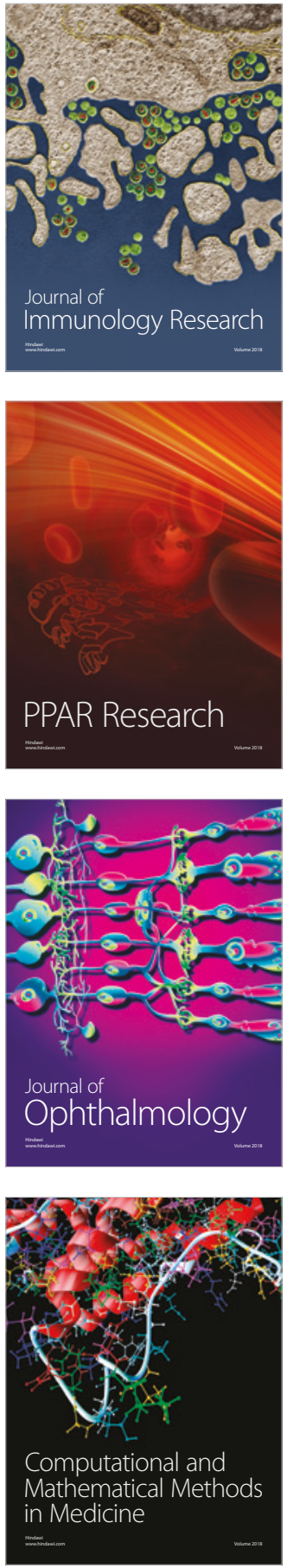

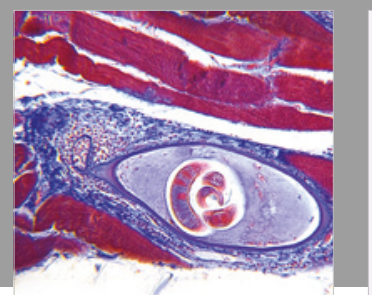

Gastroenterology Research and Practice

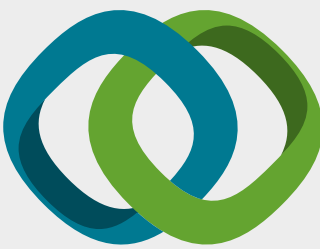

\section{Hindawi}

Submit your manuscripts at

www.hindawi.com
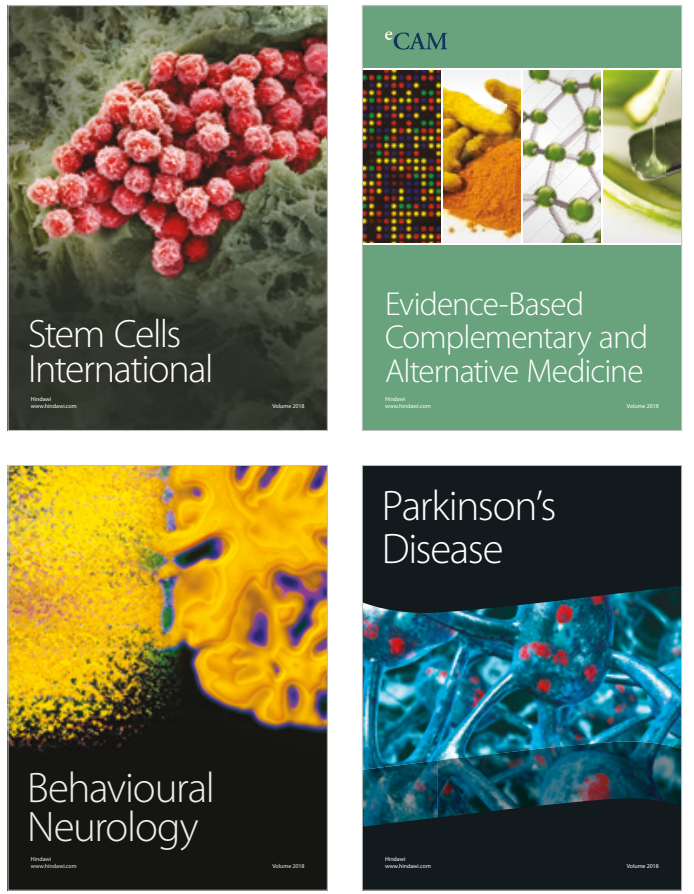

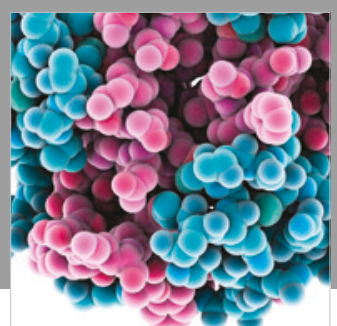

ournal of

Diabetes Research

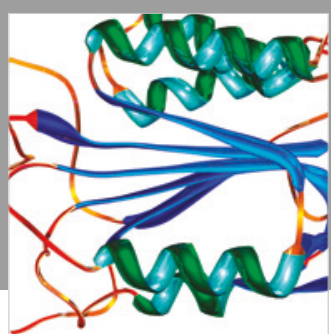

Disease Markers
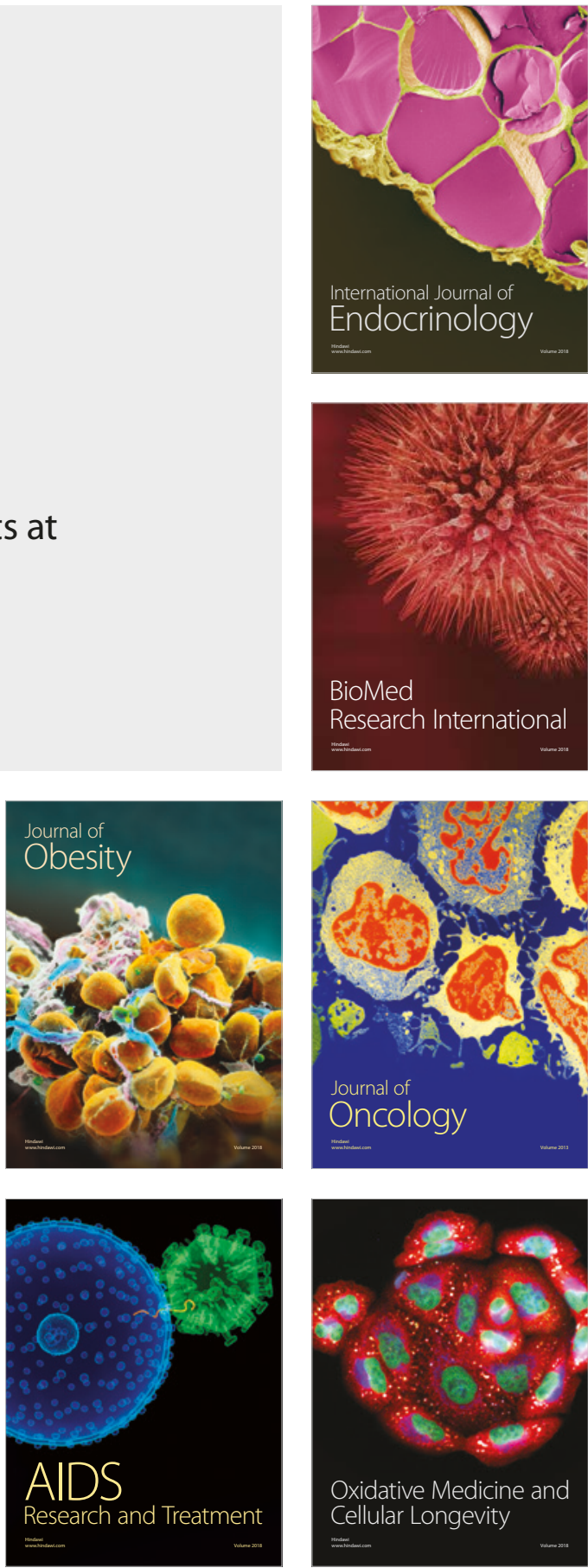